CARTA AL EDITOR

\section{INFECCIÓN POR Toxocara canis \\ EN NIÑOS DE UNA ESCUELA PÚBLICA DE IQUITOS, PERÚ}

\section{Toxocara Canis INFECTION IN CHILDREN \\ FROM A PUBLIC SCHOOL IN IQUITOS, PERU}

\author{
Renata Pulcha-Ugarte@1,a, Victor Figueroa-Vásquez@1,a, \\ Maria Lazo-Porras (1) 2,3,a,b, Ciro Maguiña-Vargas (11,a,c \\ 1 Universidad Peruana Cayetano Heredia, Lima, Perú. \\ 2 CRONICAS Centre of Excellence in Chronic Diseases, Universidad \\ Peruana Cayetano Heredia, Lima, Perú. \\ 3 Departamento de Medicina Tropical y Humanitaria, Hospital Universitario \\ de Ginebra y Universidad de Ginebra, Ginebra, Suiza. \\ a Médico cirujano; ${ }^{b}$ magíster en Ciencias en Investigación Epidemiológica; \\ Médico infectólogo
}

Sr. Editor: La toxocariasis es una infección causada por las larvas del nemátodo Toxocara canis y, en menos frecuencia, Toxocara catii. Esta infección se manifiesta en humanos de diferentes formas clínicas; una conocida como larva migrans visceral, la cual compromete hígado y bazo, principalmente, y la larva migrans ocular, que causa disminución de la agudeza visual secundaria a un desprendimiento de retina. Además, puede localizarse a nivel cerebral, manifestándose con convulsiones o focalizaciones. Por otra parte, es sabido que, las precarias condiciones de saneamiento básico facilitan la transmisión fecal-oral, poniendo en mayor riesgo al grupo etario infantil ${ }^{(1,2)}$. También se han descrito factores de riesgo asociados como presencia de perros (o su estado de vacunación), geofagia y concurrencia de asistencia a parques posiblemente contaminados ${ }^{(2)}$. El diagnóstico se puede realizar por biopsia, mas al ser un procedimiento invasivo se prefiere utilizar pruebas de serología que utilizan antígenos de excreción-secreción de larvas de T. canis para detectar anticuerpos. Una de las metodologías estandarizadas en Perú es la de dot-ELISA IgG, la cual utiliza un extracto soluble de Ascaris suum para remover los anticuerpos no específicos que puedan causar una reacción cruzada con Ascaris spp. Esta metodología alcanza una sensibilidad de $100 \%$ y especificidad de $95 \%{ }^{(3)}$.

Citar como: Pulcha-Ugarte R, Figueroa-Vásquez V, Lazo-Porras M, Maguiña-Vargas C. Infección por Toxocara canis en niños de una escuela pública de Iquitos, Perú. Rev Peru Med Exp Salud Publica. 2021;38(2):3634. doi: https://doi.org/10.17843/rpmesp.2021.382.7580.

Correspondencia: Renata Pulcha Ugarte; pulcharenata@gmail.com

Recibido: 13/03/2021 Aprobado: 12/05/2021 En línea: 02/07/2021
Incluso tratándose de una enfermedad desatendida, en un metaanálisis realizado por Rostami et al., se encontró un total de 250 estudios de seroprevalencia alrededor del mundo, sumando 265327 participantes, que demostró una seroprevalencia global de toxocariasis de $19 \%{ }^{(4)}$. En el Perú, se han estudiado seroprevalencias en provincias con resultados de $27,9 \%$ en niños de Chanchamayo, Junín ${ }^{(5)}$ y 32,4\% en niños escolares en Lambayeque ${ }^{(6)}$. Breña et al., demostraron $46 \%$ de positividad en niños del distrito de San Juan de Lurigancho en la ciudad de Lima ${ }^{(7)}$. El objetivo de nuestro estudio fue establecer la frecuencia de infección de toxocariasis en niños de una escuela pública en la Amazonía peruana y evaluar potenciales asociaciones con los factores de riesgo descritos en la literatura.

El presente estudio es descriptivo de corte transversal, realizado en el 2018 en una comunidad de la selva del Perú, donde viven 580 habitantes, de los cuales 108 son niños que acuden al colegio público local. Se aplicó un muestreo no probabilístico por conveniencia para recolectar muestras de sangre de $5 \mathrm{~mL}$ a niños de 4 a 12 años, los cuales aceptaron participar y contaban con consentimiento de los padres. Las muestras se llevaron en cadena de frio al laboratorio del Instituto de Medicina Tropical Daniel A. Carrión de la Universidad Nacional Mayor de San Marcos, donde se analizaron con la prueba de dot-ELISA-IgG. Se estimó la frecuencia de toxocariasis. Además, se aplicó la prueba de Chi cuadrado o prueba exacta de Fisher para establecer la asociación entre toxocariasis y características demográficas y potenciales factores de riesgo. Este proyecto de investigación fue aprobado por el Comité de Ética de la Universidad Peruana Cayetano Heredia y autorizado por la dirección del colegio.

El número total de participantes fue de 61 niños. Un $36,1 \%$ de la muestra presentó infección por T. canis. Dentro de la frecuencia de toxocariasis para cada grupo específico, se determinó mayor frecuencia de infección $(43,9 \%)$ en los niños de 4 a 9 años, que en aquellos con 10 a 12 años $(20,0 \%)$. Respecto a la frecuencia de infección entre los sexos, los varones tuvieron mayor frecuencia con un resultado de $39,4 \%$ vs. $32,1 \%(p=0,557)$ en las mujeres. Otras frecuencias demostraron resultados de $32,7 \%$ en el grupo que incurría en geofagia de 0 a 4 veces por semana vs $50 \%$ en aquellos que lo hacían 5 o más días (Tabla 1). De los 23 participantes que tenían un perro en casa, solo 4 manifestaron haberlo desparasitado.

Nuestros hallazgos son consistentes con los encontrados en otras regiones rurales de Perú. Esto se debe a que en este tipo de áreas es poco probable encontrar un control canino adecuado, y muchos de estos animales depositan sus heces en suelos limpios, sin estar previamente desparasitados. Por otra parte, los hábitos de higiene se llevan a cabo par- 
cialmente, pues no se cuenta con agua potable, las personas acostumbran a caminar con pies descalzos y hay constante contacto con animales, perros incluidos.

En conclusión, la toxocariasis es una enfermedad desa- tendida en el mundo, pero manifiestamente presente en el Perú, en niños de una escuela de Iquitos en un 36,1\%. Por lo tanto, amerita promover y realizar esfuerzos para prevenir su transmisión.

Tabla. Características de la infección por Toxocara canis en niños de una escuela pública en Iquitos, Perú 2018.

\begin{tabular}{|c|c|c|c|}
\hline Variable & $\begin{array}{c}\text { Con toxocariosis }(n=22) \\
n(\%)\end{array}$ & $\begin{array}{c}\text { Sin toxocariosis }(\mathbf{n}=39) \\
n(\%)\end{array}$ & Valor de $\mathbf{p}$ \\
\hline \multicolumn{4}{|l|}{ Edad (años) } \\
\hline 4 a 9 & $18(43,9)$ & $23(56,1)$ & $0,059^{*}$ \\
\hline 10 a 12 & $4(20,0)$ & $16(80,0)$ & \\
\hline \multicolumn{4}{|l|}{ Sexo } \\
\hline Femenino & $9(32,1)$ & $19(67,9)$ & 0,557 \\
\hline Masculino & $13(39,4)$ & $20(60,6)$ & \\
\hline \multicolumn{4}{|c|}{ Tenencia de perros } \\
\hline Sí & $7(30,4)$ & $16(69,6)$ & 0,476 \\
\hline No & $15(39,5)$ & $23(60,5)$ & \\
\hline \multicolumn{4}{|c|}{ Asistencia a parques posiblemente contaminados durante la semana } \\
\hline 0 a 4 días & $4(28,6)$ & $10(71,4)$ & $0,370^{*}$ \\
\hline$>4$ días & $18(38,3)$ & $29(61,7)$ & \\
\hline \multicolumn{4}{|c|}{ Geofagia durante la semana (días) } \\
\hline 0 a 4 & $16(32,7)$ & $33(67,3)$ & 0,262 \\
\hline$>4$ & $6(50,0)$ & $6(50,0)$ & \\
\hline \multicolumn{4}{|c|}{ Lavado de manos durante la semana (días) } \\
\hline 0 a 4 & $1(50,0)$ & $1(50,0)$ & $0,595^{*}$ \\
\hline$>4$ & $21(35,6)$ & $38(64,4)$ & \\
\hline \multicolumn{4}{|c|}{ Lavado de vegetales durante la semana (días) } \\
\hline 0 a 4 & $1(20,0)$ & $4(80,0)$ & $0,401^{*}$ \\
\hline$>4$ & $21(37,5)$ & $35(62,5)$ & \\
\hline
\end{tabular}

* Prueba exacta de Fisher

\section{REFERENCIAS BIBLIOGRÁFICAS}

1. Macpherson CN. The epidemiology and public health importance of toxocariasis: a zoonosis of global importance. Int J Parasitol. 2013;43(1213):999-1008.

2. Breña J, Hernández R, Hernández A, Castañeda R, Espinoza Y, Roldán $\mathrm{W}$, et al. Toxocariosis humana en el Perú: aspectos epidemiológicos, clínicos y de laboratorio. Acta Méd Peruana. 2011; 28(4): 228-236.

3. Roldán W, Cornejo W, Espinoza Y. Evaluation of the dot enzyme-linked immunosorbent assay in comparison with standard ELISA for the immunodiagnosis of human toxocariasis. Mem Inst Oswaldo Cruz. 2006;101(1):71-74. doi: 10.1590/s0074-02762006000100013.

4. Rostami A, Riahi S, Holland C, Taghipour A, Khalili-Fomeshi M Fakhri Y, et al. Seroprevalence estimates for Toxocariosis in people worldwide: A systematic review and meta-analysis. PLoS Negl Trop Dis. 2019;13(12):e0007809. doi: 10.1371/journal.pntd.0007809

5. Huapaya HP, Espinoza Y, Roldán W, Jiménez S. Toxocariosis humana: ¿problema de salud pública?. An Fac Med. 2009;70(4):283-290.

6. Espinoza Y, Huapaya P, Roldán W, Jiménez S, Arce Z, Lopez E. Clinical and serological evidence of Toxocara infection in school children from Morrope District, Lambayeque, Peru. Rev Inst Med Trop São Paulo. 2008; 50(2):101-105.

7. Breña JP, Huayanay L, Hernández RA, Espinoza Y, Roldán W, Maguiña CP. Seroprevalencia de Toxocariosis en niños de Instituciones Educativas del distrito de San Juan de Lurigancho. 56th Annual Meeting of the American Society of Tropical Medicine and Hygiene, 3-8 November 2007, Philadelphia, USA. En: Am J Trop Med Hyg. 2007; 77(5):110 (Abstract) 